TURIZAM

Volume 15 , Issue 4

135-147 (2011)

\title{
Ethical Conduct of Employees in Tourist Organizations in Novi Sad (Serbia)
}

\author{
Ana Jovičić*, Tatjana Pivac*, Aleksandra Dragin* \\ Received: July 2011 | Accepted: November 2011
}

\begin{abstract}
The conduct of employees in tourism, but also all the other factors that participate indirectly in the tourism industry of Novi Sad contributes greatly to creating the image of Novi Sad in the domestic and international market. In that sense, ethical conduct and respect of the code of ethics is the basis of acquiring a good image of Novi Sad and improving the tourist product of Novi Sad. Business ethics includes principles and rules of conduct based on general and business culture and the principles and rules that dominate in interpersonal communication. The complex of factors, which interact, influence ethical behaviour of those who are directly and indirectly employed in tourism industry. Those are characteristics that each individual have, which he/she brings into the organization, and also the culture of the organization. The subject of this paper is to explore forms of unethical behaviour in organizations that are directly or indirectly involved in the tourism industry, with which tourists and local population meet in Novi Sad. The aim of this work is to come to conclusions analyzing, which will help us to see the current situation and take measures that will improve the tourist product of Novi Sad. The study concluded that organizations that participate in the creation of tourist product of Novi Sad mostly do not have an ethical code of conduct, and those that have it, do not apply it to the necessary extent. In that sense it is necessary to motivate employees and to properly implement a code of ethics through ethical training, which is usually present in organizations only in normative, without the employees knowing the content of this code, as well as its importance for the organization and reflecting on the wider social level.
\end{abstract}

Key words: ethics, tourism, behaviour of employees, Novi Sad

\section{Introduction}

Novi Sad is an important tourist destination for domestic and foreign tourists. Tourist product of Novi Sad is the synthesis of a great geographical location, many natural and cultural treasures, built infrastructure, accommodation, and good transport links, opportunities for fun and entertainment and exceptional friendliness of local people towards tourists. The

\footnotetext{
* University of Novi Sad, Faculty of Sciences, Department of Geography, Tourism and Hotel Management, Trg Dositeja Obradovića 3, Novi Sad, corresponding author: ana.jovicic@fondmt.rs
} 
behaviour of employees in tourism, but also all the other factors that participate indirectly in the tourism industry of Novi Sad contributes greatly to creating the image of Novi Sad in the domestic and international market. In that sense, ethical conduct and respect of the code of ethics is the basis of acquiring a good image of Novi Sad and improving the tourist product of Novi Sad.

Solution to a number of issues in business is not possible if the starting point is not based on precisely formulated ethical norms. Ethics refers to principles of behaviour by which individuals or groups are guided, in particular the standards used to shape the conduct of people.

In developed market economies, the notion of moral business took on huge proportions and irepresents an integral part, required reading, not only of every university or college, but of every business man and every organization.

The subject of this paper is to explore forms of unethical behaviour in organizations that are directly or indirectly involved in the tourism industry, with which tourists and local population meet in Novi Sad. The aim of this work is to come to conclusions analyzing, which will help us to see the current situation and take measures that will improve the tourist product of Novi Sad. We have started the study with general hypothesis: Tourist Organization of Novi Sad does not have a legal code of ethics, and the participants, i.e. employees in the tourism industry are not sufficiently aware of the existence of ethical norms.

Methods used in the paper are: office research, deductive method and research through survey. The existence of codes of ethics of tourist organizations has a positive impact and encourages the development of correct relations of employees, customers and the environment in which the organization operates, and standard-setting increases service quality and satisfaction of tourists and guests.

\section{Term of business ethics}

Within the new civilization change, cultural clashes and contacts, conflicts of interest and the growing conflict in economics and business, in communications and information technologies, conflicting ideologies and expressed political conflicts about world domination it leads to general decline of moral values and moral standards, and there arouse inevitable questions about morality and ethics in business, the direct practice of business-ethical conduct. A new concept of business conduct has been created - business ethics. Business ethics is based on respect for the rights and interests of others and achieving general social interests, which include quality working environment where business success, competitiveness and profits do not depend on anything else than the rights and duties that are applied in decision making (Trifunovic, 2005:2I). The business ethics means the organizational or corporate culture, which refers to the rules of ethical conduct, core systems of values, ethical principles and specific ethical rules that the company is trying to implement. These designed elements of corporate culture in form of rules of ethical conduct that should be applied and achieved are: keeping promises, benevolence, helping others, respect for other people. From these elements were created moral rules which every organization should follow, as well as the ethical norms that determine behaviour.

Business ethics means also business communication that emerged from the relationship of business culture and ethics in business. Business culture is important because it is based on the general culture, language culture, and etiquette, culture of oral and written commu- 
nication. All that is important for the contact of business partners, employees in the tourism industry and tourists, i.e. guests. Business ethics means also values of moral behaviour, and also standards of ethical conduct embodied in codes of professional or business conduct.

The main issues of business ethics can be classified into four areas: the relationship between business subjects and clients, the relationship between employers and employees, the nature and value of business organizations and the nature and value of the market (Ratkovic Njegovan, 2009:26).

The subject of business ethics is a set of moral rules of conduct in all business activities directed toward a successful and profitable business. The standards are based on values that are based on fundamental ethical principles, their content is expressed by the judgements of the good and bad, successful and unsuccessful business behaviour, and their goal is to oblige all participants in the overall business processes on ethical behaviour. In such way determined business ethics is a theoretical discipline that analytically approaches to the explanation of different moral view about the fundamental values and ethical principles that are applicable on the entire area of business.

Since the business ethics has always been heavily influenced by society and the environment in which it flourished, the society, with its organizations and institutions, its culture, habits and values, has created an appropriate legal and political environment that influenced ethics in business. Ethics in business is also influenced by man's conduct, which is again a product of society and social relations within which the moral opinion of individual is shaped in relation to what is good and right and what is not.

Every society consists of people who are connected to some common goals and whose activities are regulated so that these objectives are successfully implemented through the institutions of society. The most influential institutions in modern societies are economic institutions. They determine who and how would produce various goods and services, how the jobs would be organized, which resources would be used, how the products and revenue would be distributed among members of society. Business ethics represents a field of two different perspectives: moral or ethical and business or economic perspective. The ethical perspective is based on moral values: honesty, justice, dependability, rights and duties, all that can be characterized as good or morally right. The business perspective is based on economic value: benefits, profit, cost, price, efficiency, competition. The subject of business ethics is just the average, which is obtained by crossing the moral and economic aspects of the business (Petrovic, 2007:35).

It is possible to view ethics in business on four levels:

- The level of the individual in which everyone encounters himself/herself;

- The level of organization that relates with the relevant moral principles within the organization by all internal stakeholders, i.e. employees, shareholders, managers;

- The level of external stakeholders, i.e. clients or guests, unions, government, media, competitors;

- The social level which refers to the moral and ethical issues at the level of the entire community (Eric, 2000:193).

Ethical business conduct in terms of undisputed rule of law of market and tough competition, is often exposed to many temptations, or ethical dilemmas such as: greed, statements that lead to wrong conclusions about the quality of products and services, avoiding to keep the given word or cheating in terms of agreed conditions and deadlines, lack of loyalty to the organization, tolerance of unethical conduct, corrupting etc (Raseta, Kosar, 2005:7). These 
unethical business moves that often occur in practice can cause far-reaching negative consequences for customers, business partners and the organizations. The study that follows will show the basic forms of unethical behaviour that the respondents have experienced as well as organizations that are directly or indirectly involved in the tourism industry of Novi Sad and which in a greater or lesser extent show certain forms of unethical behaviour.

\section{The importance of ethics and moral values of management and business etiqette in tourism}

Managers in tourism and other tourism-related organizations often need to know more than they have gained through formal education or what they have learned in the family. Particularly important are rules of good manners, in order to meet needs the clients or guests in the best way. Also, the tourism manager should have a number of characteristics such as kindness, resourcefulness, intelligence, persistence, initiative, earnestness, honesty, benevolence. However, the manager should first of all be a man/woman of high moral values, i.e. he/she should have knowledge how to handle the various situations in which he/she can come to. The manager has another important role-a role of a model, i.e. a manager is the person employees look up to and the person who is a model for the employees.

The main characteristics of business ethics refer to personal respect, mutual respect and trust, respecting diversity, overcoming differences and respecting others' interests, protection of dignity, responsibility and duty to the others, helping each other, keeping promises and given words, respecting good business customs and intentions, business compromise, humanity. Without these characteristics neither manager, nor organization can hope for success. In addition to moral personality traits, characteristics of business ethics are expressed also through the possession of intellectual abilities that enable rapid inclusion and rapid adaptation to changes, the authority that is most easily acquired through honest and fair treatment of its associates, through the energy, ambition, flexibility, creativity, imagination, optimism and communication skills. Business ethics obliges all participants in the business, especially managers. Managers should be moral persons with developed and adopted internal feeling that is particularly true of moral responsibility. In addition to education and a sense for management, the manager should also have a distinct sense of interpersonal relations, ability to comprehend and understand the social (and natural) environment, to know the psychology of behaviour, mentality, ethical standards and moral systems, value systems, in the spirit of the times which it operates.

The main new values or principles of moral conduct in business relations should be based on the principles of ethical humanism. Business ethics should, as a general unwritten set of ethical norms and values which defines professional conduct at all times, be based on the dignity and autonomy of all participants in the business process, the freedom of choice that a person could follow his/her business instinct as long as he/she does not endanger other participants in business relationships, which is important because of the diversity of value and business systems.

In addition to respect for diversity, for business ethics is important to define ethics of excellence and business standards such as creativity, rationality, self-selection, ability, fairness, honesty, adaptability to the situation, keeping promises, fair business cooperation.

It is important to increase the level of their own business responsibility and accountability to business partners, respect the needs and interests of others, to act humanely in every business contact, bring back to business life moral responsibility, moral virtue and moral conduct. 
The golden rule in business that managers should apply is called the IMPULS and is an acronym of words in Serbian that in English mean Appearance (Izgled), Manners (Maniri), Honesty (Poštenje), Respect (Uvažavanje), Personality (Ličnost), Style (Stil) and Tact (Takt) (Robinson, 2OO2:I3). Having these characteristics will affect the positive impression that managers leave on their business partners or customers.

Polite behaviour or good conduct should be characteristics of every manager who works in tourism or hotel management. Manners and respect for etiquette can often be identified with a high level of business morality.

Etiquette can be defined as a set of written or unwritten rules of good conduct, the appropriate behaviour in a society. Etiquette is a set of traditions and customs, based on kindness, ethics, logic, consciousness which has developed over a long period of time. Business etiquette can be defined as a set of informal rules and obligations that derive from tradition, with them the manager realizes better communication, becoming more successful in carrying out his/her business tasks (Cerovic, 2003:I77). The existence of etiquette is the obligation of every organization and individual involved in the tourism industry. However, we will see whether in Novi Sad, business etiquette in these organizations is actually being applied.

\section{The role of code of ethics and social responsibility in tourism}

Expression of unethical behaviour depends on the individual and the organization in which the individual is employed. Codes of ethics have great importance for regulating the conduct of employees in organizations. The concept of a code derived from the Latin word "codex" which means the Legal Code. Code is a set of principles in the field of morals and professional ethics, as guidelines for professional work and public activities of all members of the organization (Ratkovic Njegovan, 2009:29). It is a set of rules, norms of moral character that regulate the behaviour of members of a profession or they have a universal character in a society. Ethical codes define values and behaviour based on them; establish a higher moral level in organization, such behaviours expected from employees or those that will not be tolerated. This establishes the norms and beliefs of the organization, and through this an intention to encourage a desirable model of thinking (http://www.linkelearning.com/dlmaterijali/materijali/DLPE/SadrzajNJpdf/PE_O7.pdf).

Ethical codes define ethical standards, regulate norms of ethical conduct, as well as sanctions in case of failure and connect them with the activity of the organization. Organizations adopt codes of ethics in order to improve the relationship to moral problems. It is the written rules of conduct while making business decisions in different situations. Many companies and organizations in the tourism industry have developed codes of ethics. Codes of ethics are different from the ethical rules. With the codes of ethics we want to raise a higher moral level of the employees. It means that ethics become institutionalized.

In recent years, a large number of codes of ethics have been created which aim to help businessmen to behave in ethical and morally responsible way, specifying and clarifying how the general moral principles and standards can be applied on the type of business or products (services) of the given organization. Codes of ethics should play an important role by directing, provide support, encourage and assist in resolving of specific, morally controversial issues with which managers, employees or members of a profession within the organization are faced.

Understanding the code of ethics is important and necessary. Making business decisions is affected by a large number of factors, and if the ethical environment is healthier, then the 
experts are more rigorous to the troubled practice. In creating the codes of ethics all employees should be involved, because in that way it is easier to define attitudes about what is moral and what is immoral behaviour, both in relation to potential consumers, i.e. public, and in mutual relation of the employees to each other. The most important central moral ideas in a number of company codes of ethics are: fairness, honesty, respect for human dignity and respect for the public. Every company in its business activities should balance the four fundamental moral values:

- Principle I: Business activities must be characterized by correctness. Correctness should provide equal treatment and equal opportunity to all market participants.

- Principle 2: Business activities must be characterized by sincerity. Honesty should ensure openness, the will for the truth and fulfilment of promises.

- Principle 3: Business activities must be characterized by respect for human dignity, should show special concern for the less powerful and less able.

- Principle 4: Business activities must be characterized by the respect for public. This should mean that business activities look at potential consumers and the general public as an objective, not only as means (http://www.preduzetnik.com/magazine/2009/03/znacaj-i-neophodnost-uspostavljanja-etickog-kodeksa/).

These principles of business activities should be an integral part and the foundation of any ethical code. If companied do not devote their full attention to ethical issues and moral dilemmas in their management, errors will result in increasingly negative attitude of consumers and distort the company's image in public.

Tourism nowadays has a major impact on the global economy which is why there was the necessity of defining a code of ethics in tourism. In October 1999, the General Assembly of the World Tourism Organization in Santiago, Chile adopted the Global Code of Ethics for Tourism. The content of this international code which is binding to all WTO member states was systematized in the following ten points:

- Tourism's contribution to mutual understanding and respect among people and societies;

- Tourism as means for individual and collective fulfilment;

- Tourism, a factor of sustainable development;

- Tourism- user of the cultural heritage of mankind and a factor of its improvement;

- Tourism - a beneficial activity for countries, communities and hosts;

- Obligations of independent travel professionals responsible for development;

- Right to tourism;

- Liberty of tourist movements;

- The rights of employees and entrepreneurs in the tourism industry;

- Implementation of the Global Code of Ethics for Tourism.

This code is a liability, the basis and guidelines for the establishment of codes of every organization which is a participant in the tourism industry.

Successful organizations in tourism are able to reconcile economic responsibility, ethical responsibility, environmental responsibility, legal responsibility and social responsibility. Economic responsibility means responsibility for fulfilling the goals of the organization - in profitable organizations it means profit, which is why it is called economic responsibility. Legal responsibility means respecting the laws and regulations, but also internal documents of the organization. Ethical responsibility has already been explained in detail and 
means a set and application of personal norms in business and achieving goals of the organization. Ecological responsibility involves examining the relations of the organization and the environment in which it operates and the development of such business that will not have a negative effect on the nature and wildlife. Liability which involves the likelihood that someone would answer for one of his/her action or may be the subject to sanction of a norm, is a complex concept, because the complexity involves the relation of man to society, but also his relationship with himself. Social responsibility is largely associated with ethical business management and includes the obligation of management to create appropriate choices and take those actions which will contribute to the welfare and interests of society and organizations. Tourist organization needs to operate in a socially responsible way and to contribute to solving problems in society through employment and correct payment of employees, it has an impact on the prevention and resolution of the surrounding environmental problems, affects the improvement of education, arts and health of the community and improves government administration enabling the involvement of managers in government positions (Vukicevic, 2007, 69).

\section{Results of research}

Based on research by the survey, we came to certain information related to the behaviour of tourists, their habits in terms of travel and reasons for travel. The focus of the survey are the types of unethical behaviour, as well as places where they are represented (museums, religious buildings, hotels, public transport etc.). Survey was conducted on a sample of 75 respondents, anonymously, in Novi Sad, in a continuous period from November 2OIO, to February 2OII. The survey was conducted by students of master studies of Faculty of Science, Department of Geography, Tourism and Hotel Management, within the subject Ethics in tourism, through random sampling, using interviews. The survey consisted of three groups of questions. The first group of questions was related to demographic characteristics of respondents, the second group of questions was related to the habits and preferences of tourists related to travels, while the third group of questions focused on the research of unethical behaviour of organizations and individuals involved in the creation of the tourism product of Novi Sad (hotels, public transport, public institutions, museums and galleries, theatres, religious buildings, tourist guides, travel agencies, shops, cafes and restaurants, banks and exchange offices, passers-by). Questions in the survey were phrased so that answers were offered or the scale from I to 5 was given according to which the respondents defined the degree of their compliance with the offered statement (I - strongly disagree, 2 disagree, 3 - not sure, 4 - agree, 5 - completely agree).

The research is particularly important because using the analysis we come to conclusions that will help us to realize the current situation in the behaviour of participants in the tourism industry of Novi Sad and take the necessary measures to improve the quality of tourism of Novi Sad. From a total of 75 respondents, 63\% were women, while $37 \%$ were men. Most of the respondents, $62 \%$ live alone, a small number of respondents were married, while very few respondents, IO\% were divorced or live cohabiting.

Most of the respondents $74 \%$ are in the age group from I9 to 29 years, and in the age group from 30 to 39 years were $19 \%$ of respondents. To the age group from 40 to 49 years belonged $6 \%$ of respondents, and $\mathrm{I} \%$ was older than $5 \mathrm{O}$. In terms of education level relationship is as follows: $35 \%$ was with secondary education, $30 \%$ - highly educated and $31 \%$ with 
master education. There were $4 \%$ of respondents with college education, while there were no respondents with elementary education and $\mathrm{PhD}$.

The majority of respondents were employed $47 \%$, and the number of unemployed respondents was 34\%. A small number of respondents claimed to be students $\mathrm{I} 2 \%$, athletes $3 \%$ and retired $4 \%$. Most of the respondents $38 \%$ had total monthly income between 15.000 and 30.000 dinars. As many as $2 \mathrm{I} \%$ of respondents had no income, while $\mathrm{I} 8 \%$ has income less than 15.000 dinars a month. Between 30.000 and 50.000 amount the income of $17 \%$ of respondents, while more than 70.000 dinars of income have only $6 \%$ of respondents.

Respondents live in Novi Sad 56\%, Belgrade 28\%, Zrenjanin I2\% and in Sid 4\%. Birthplaces of respondents are different; mostly it is the region of Serbia, Bosnia and Herzegovina and Montenegro.

When asked if they preferred to travel, over 93\% said yes, and only $7 \%$ of respondents had no desire to travel. Respondents who do not travel, as the most common reason for not travelling mentioned that they had no money for travel, which is a result of low purchasing power in Serbia, increased unemployment and high prices of package tours, as well as the adverse quality-price relationship. Leisure time and poor health are also reasons why the respondents do not travel.

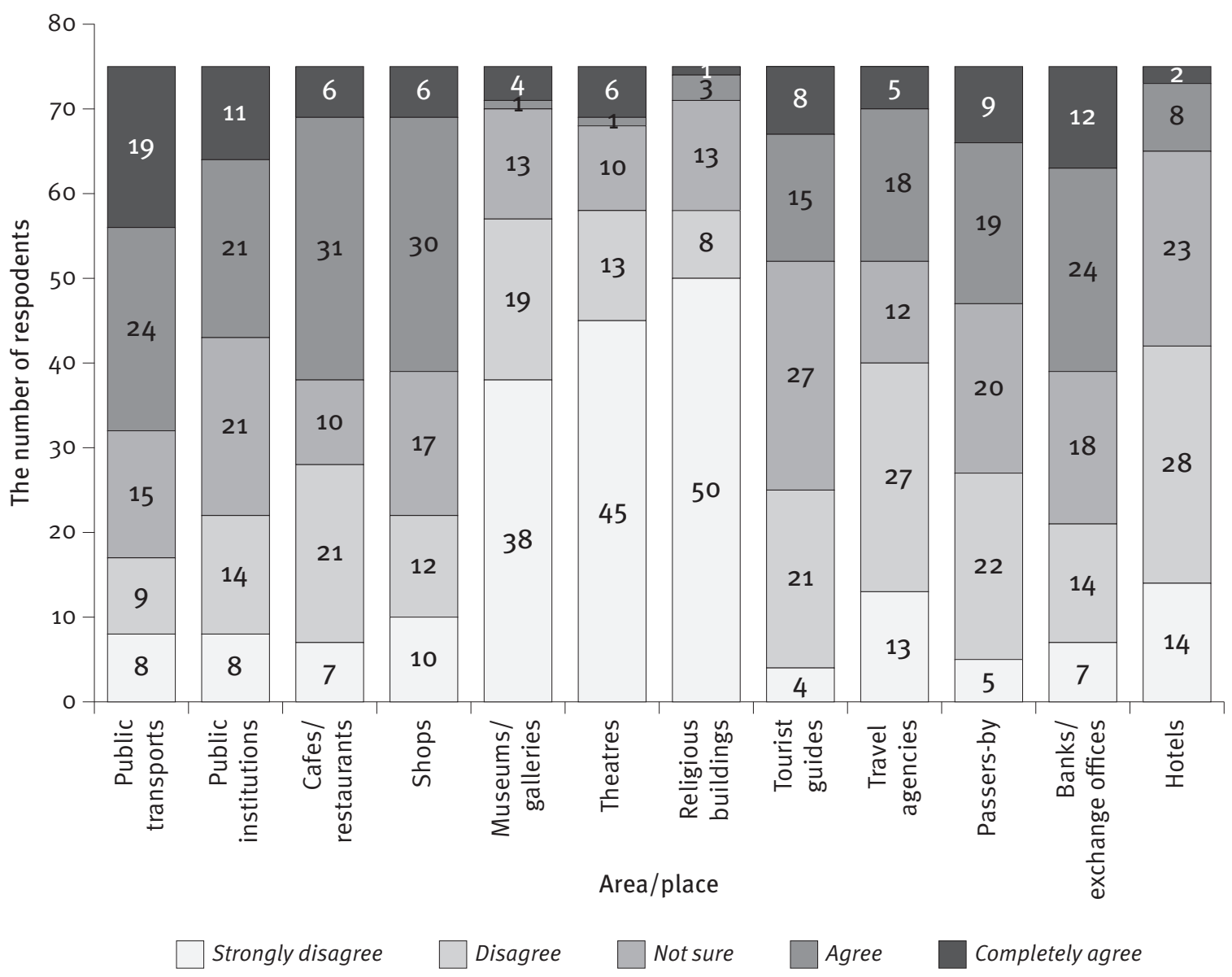

Figure 1 Unethical conduct in respect of the services in organizations of tourism in Novi Sad expressed in absolute numbers 
Respondents, who travel in most cases $39 \%$, go on trips several times a year, while $37 \%$ of respondents went on a trip once a year. The smallest portion of respondents $24 \%$, are those who rarely travel.

In the research we next tried to determine whether the respondents encountered unethical behaviour in Novi Sad, and in the focus were the organizations which mostly create the quality of tourist product of Novi Sad: hotels, public transport, public institutions, museums and galleries, theatres, religious buildings, tourist guides, travel agencies, shops, cafes and restaurants, banks and exchange offices, passers-by.

When asked in which areas and in what situations they have experienced unethical behaviour on a scale I-5 (I - strongly disagree, 2 - disagree, 3 - not sure, 4 - agree, 5 - completely agree) respondents assessed direct and indirect participants in the tourism industry of Novi Sad. Respondents, 57\% of them encountered most commonly the misconduct/unethical behaviour in public transport, $42 \%$ of respondents in public services, $49 \%$ of respondents in cafes and restaurants, $48 \%$ at banks and exchange offices and $48 \%$ of respondents in shops. Respondents, $36 \%$ of them, were largely neutral on the issue of unethical behaviour of tour guides, and to a lesser extent, $30 \%$ of respondents were neutral in terms of unethical behaviour of hotel staff. They found the least/minimum of unethical behaviour in facilities such as theatres, religious buildings, museums and galleries.

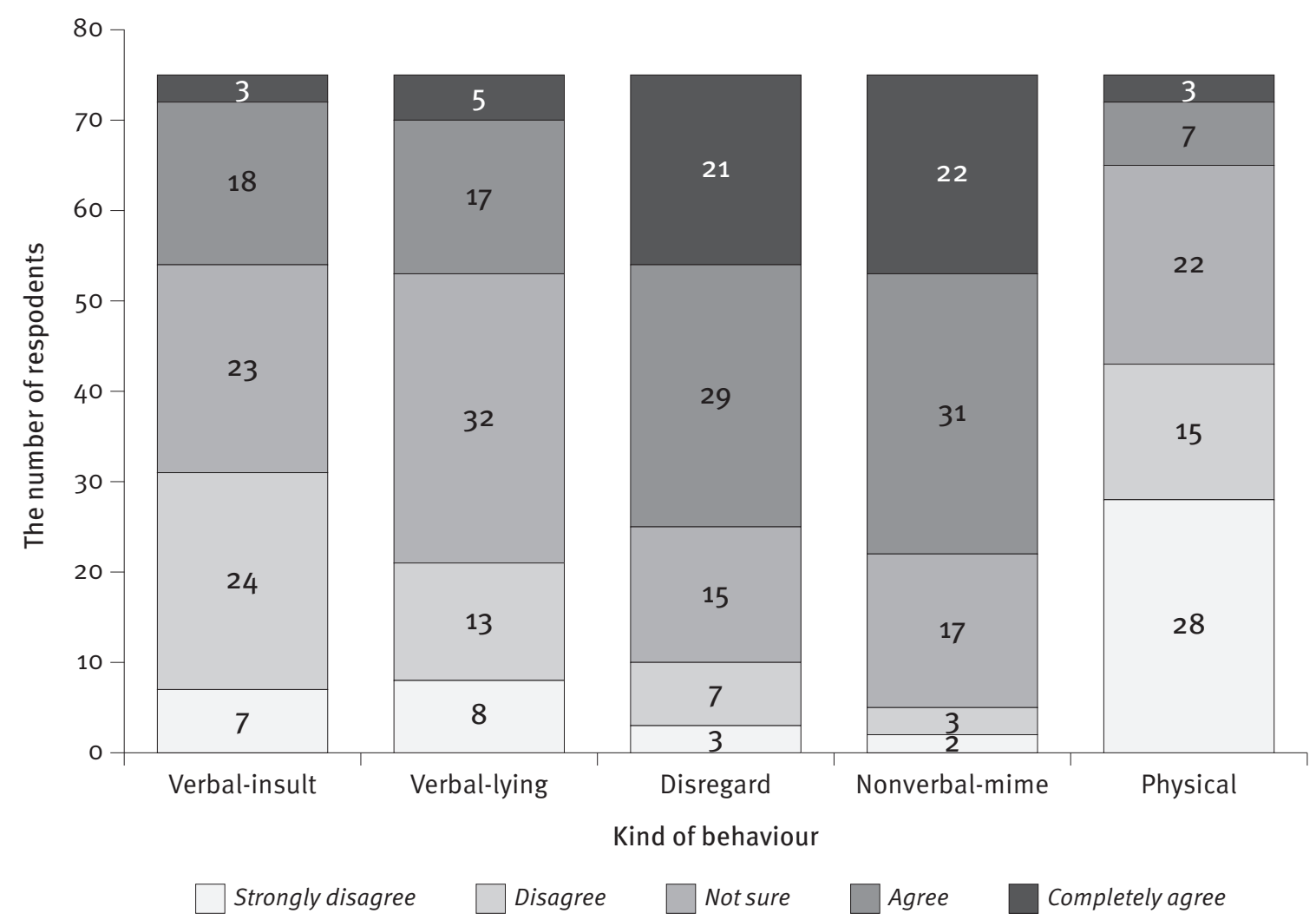

Figure 2 Forms of unethical behaviour to which the respondents were exposed in Novi Sad, expressed in absolute numbers 
Hotels as direct participants in the tourism industry were: evaluated as positive and $56 \%$ of respondents did not encounter unethical behaviour of/by the staff. A very similar situation is related to the travel agencies where $53 \%$ of respondents did not experience unethical behaviour, tourist guides with $37 \%$ of respondents who have not met with unethical behaviour and cafes and restaurants where the view on the ethical behaviour is different among the respondents. This data tells us that in Novi Sad there is awareness of the importance of tourism development and the ways that tourism can be developed and promoted.

In terms of unethical behaviour the respondents largely mentioned disregard, $66 \%$ of respondents, and non-verbal behaviour-mimicry-70\% of respondents. Neutral stance respondents had about the unethical behaviour in the verbal sense-lie. At a minimum the respondents faced with physical violence, $57 \%$ of them, as a form of unethical behaviour and insults $3 \mathrm{I} \%$ of respondents. By crossing the demographic characteristics of respondents with offered answers related to the unethical conduct of organizations of tourist economy of Novi Sad and the types of unethical behaviour, we could not establish certain regularities from which a significant conclusion for research could be drawn.

\section{Measures for improving the ethical climate in tourism organization}

Violation of ethics can lead even the most respected and most responsible companies to operate recklessly and maliciously. Misconduct in the business world is important in three areas: the area of law, within the economically-social issues and in giving advantage to their own interests. To achieve as much profit is for many managers sufficient reason to exceed moral line and to ignore the ethical principles of population and employees.

Ethics serves as a guiding principle in decision-making for managers and as an ally to all employees while they are performing their business activities. The importance of ethics grows proportionately with the consequences of decisions and behaviour of employees in tourism. If the decisions have major impact on other people, then the importance of ethical conduct of the employees is greater.

Ethical or unethical behaviour of the organization's management is usually in focus. Managers are always guilty in the organization. Once they are blamed for what they did, and the other time for what they did not do. It is rightly questioned whether the ethics could in time at managers cause the fear of inaction (Desseler, 2007:254).

The essence of managerial responsibilities in organizations which can be found in tourism, such as international hotel chains or tour-operators, is reflected in actions they have taken on the basis of individual initiative, actions taken on the basis of personal initiative, actions taken on the basis of others' directives, the behaviour of subordinates who follow their instructions and ethical behaviour of the organization as a whole. Managers have to be prepared to take the moral risk in decision-making for potential harm and negative consequences to which members of the organization may be exposed to.

Within the organization it is possible that there is the existence of different measures for improving the ethical climate and social responsibility of the organization are numerous: leading by example, a code of ethics, ethical structures, ethical structures and ethical hotlines and supportive whistle-blowers (Cerovic, 2003:I75). Leading with the example refers to the principle that personal example is the best way to influence employees. Without the leadership by example it is hard to imagine the successful and high quality development of ethical behaviour in an organization. Code of ethics helps employees to adapt their behav- 
iour to the environment of the organization and to distinguish between acceptable and unacceptable behaviour. Ethical structures represent different organs of the organization. There is a difference between Ethics Committee, a group of managers who takes measures that employees act ethically and Ethics representative, a specialist/expert in business ethics that is appointed as an independent board member and acts as its conscience. Ethics training and ethics hotlines represent ways of teaching ethics so that employees could develop ethical behaviour. Trainings cover topics from ethics, and ethics hotlines are special telephone lines that employees use to report ethical concerns. Supporting whistle-blowers help employees to expose illegal, immoral or illicit practices of the employer. Then the employees report to the owner about the incident, and then if nothing is done, management, the ethics committee or other ethical bodies in the organization are informed. Serbian market, which is still in transition, does not care especially for morality and ethics. In a transitional society as ours, where the transition takes a long time, where the traditional old values are lost, and new values have not been defined and adopted, it is difficult to expect ethical behaviour. A number of business transactions are not regulated by appropriate legislation, which gives a wide space for illegal, and above all immoral and unethical conduct of business entities, i.e. market participants. The above is especially true in private business, where most jobs are done without a track record, which gives the biggest possibility for fraud. Also, lack of motivation of employees in organizations such as public transportation, restaurants, cafes and similar, due to poor career development and low wages, represent a significant aspect of employee dissatisfaction and showing of unethical conduct towards tourists, but also local population in Novi Sad. Therefore, besides the need for regulation, motivation of employees in tourism is an important aspect of improving the tourism product of Novi Sad. The main causes of low motivation at work are: monotonous repetitive work; professional skills are not enough applied; poor working conditions; employees are overloaded with work; lack of recognition for a job that is well done; lack of feedback about how jobs have been done; lack of advancement opportunities; a low position in the organization; poor interpersonal relationships; little or no responsibility for the taken job; too strict control, etc. (Raseta, Kosar, 2005:I39).

To increase motivation, managers and employers should ensure positive effect of factors that contribute to job satisfaction. The factors that cause dissatisfaction should be removed or reduced, but also promote the factors that contribute to increased satisfaction at work. Herzberg suggests that the goal for managers should be "enrichment of place of work". This can be achieved by taking the following actions: elimination of some forms of supervision, while encouraging responsibility of employees; increasing responsibility of individuals for their own work; giving comprehensive work tasks to every individual; giving more authority to individual employees; submitting a report directly to individuals rather than through intermediaries (e.g. the boss); by introducing new and challenging tasks that have not been executed; giving to individuals tasks that contribute to their professional development (Thompson, 2000:85).

All this compels employers to strive to provide better and improved quality of employee training in business ethics. Nowadays, the ethical education of employees represents a problem that is very currant. The essence of ethical training in the Serbian market is among the drivers of business activities, such as: small and medium-sized organizations, companies, government institutions, agencies and educational institutions to develop awareness of the existence of certain moral problems related to concrete production and service activities and other business activities on the market. It is important for modern businessman to understand the problem of lack of ethics in generating income and to become aware that business and ethics in any society cannot be treated as separate categories. 
It is necessary to start changes from the education in tourism. The old training programs and courses in tourism need to be redesigned and enhanced, and the foundation for further upgrading and learning needs to be precisely the knowledge related to a particular destination, political and ethical knowledge and skills, management skills with special emphasis on human resources management and knowledge related to Information Technology (Sheldon et al, 2008).

According to everything mentioned and conducted in the research, we conclude that the overall quality and ethics in tourism and services in Novi Sad, can significantly increase not only by the expansion of tourist facilities, but above all by professional and modern education of employees in this area, which will also for the basis have their knowledge of traditional and specific elements of the Vojvodina region and hospitality, as a kind of brand. The special quality to the business charm, beauty and ethics in tourism behaviour, can provide a team of educated managers with traditional business manners that characterized this region.

\section{Conclusion}

Business ethics is an integral part of business conduct. Under the business ethics are included principles and rules of conduct based on general and business culture and the principles and rules that dominate in interpersonal communication. Business ethics is a field of two different perspectives: moral, or ethical and business or economic perspective. The complex of factors that interact to influence ethic behaviour, both directly and indirectly employed in the tourism industry. These are characteristics that each individual have, which he/she brings into the organization, as well as the culture of the organization.

The study concluded that organizations which participate in the creation of the tourist product of Novi Sad mostly do not have an ethical code of conduct, and those that have it, do not apply it to the extent necessary. In this sense it is necessary to motivate employees and to properly and practically implement a code of ethics through ethical training, which is usually present in organizations only normative, without the knowledge of employees about the contents of this code, as well as its importance for the organization and reflecting on the wider social level. This by study confirmed lack is of special importance for the Tourist Organization of Novi Sad, as the representative of tourism industry, which as soon as possible should secure the possession and use of ethical codes, which will by the example influence the other participants of tourism industry to act in this direction.

Based on the analysed results we can conclude that Novi Sad and Serbia need to ensure and promote ethical conduct in general, including the ethical conduct of all participants in the tourism industry, primarily through raising awareness of the needs for ethical conduct, then the existence of different regulations with which unethical behaviour would be punished. However, it is important to create an environment in which the level of general and professional awareness would be such that the penalty would not be required. Only in this way it is possible to provide quality of tourism products or services and to create a positive image of Novi Sad and Serbia in the global tourism market.

This research, in addition to the scientific and wider importance, has considerable practical importance because it has illuminated and pointed out one of the problems in the tourism industry of Novi Sad and has given guidelines for eliminating this problem, which should contribute to improving the quality of tourism of Novi Sad and thereby contribute to greater income from tourism. 


\section{References}

Cerovic, Z. (2003): Hotel Management, Faculty of Tourism and Hotel Management Opatija, Opatija

Dessler, G. (2007): Fundamentals of human resource management, Data status, Novi Sad

Eric, D. (2OOO): Introduction to Management, Faculty of Economics and Faculty of Coaching, Belgrade

Pauline Sheldon, Dan Fesenmaier, Karl Woeber, Chris Cooper, Magda Antonioli (2008): Tourism Education Futures, 2OIO-2O3O: Building the Capacity to Lead, Journal of Teaching in Travel \& Tourism, 7:3, 6I-68

Ratkovic Njegovan, B. (2009): Business Ethics, Faculty of Technical Sciences, Novi Sad

Robinson, D. (2000): Business etiquette, PS Grmec - Economic Review, Belgrade

Tomson, R. (2OOO): Leadership skills, CLIO, Belgrade

Trifunovic, S. (2005): Business Ethics, Faculty of Industrial Management, Krusevac

Vukicevic, M. (2007): Management, Faculty of Legal and Business Studies, Novi Sad

http://www.preduzetnik.com/magazine/2009/o3/znacaj-i-neophodnost-uspostavljanjaetickog-kodeksa/

http://www.link-elearning.com/dlmaterijali/materijali/DLPE/SadrzajNJpdf/PE_O7.pdf 